\title{
TOWARDS BETTER ENERGY EFFICIENCY THROUGH SYSTEMS APPROACH IN AN INDUSTRIAL FORKLIFT
}

\author{
T.A. Minav ${ }^{1}$, T. Schimmel ${ }^{2}$, K. Murashko ${ }^{3}$, R. Åman ${ }^{4}$, J.J. Pyrhönen ${ }^{3}$ and M. Pietola ${ }^{1}$ \\ ${ }^{1}$ Department of Engineering Design and Production, Aalto University, PO Box 14300, 00076 Espoo, Finland \\ ${ }^{2}$ Evonik Industries AG, Kirschenallee, 64293 Darmstadt, Germany \\ ${ }^{3}$ LUT Energy, Lappeenranta University of Technology, P.O. Box 20, 53851 Lappeenranta, Finland \\ ${ }^{4}$ LUT Mechanical Engineering, Lappeenranta University of Technology, P.O. Box 20, 53851 Lappeenranta, Finland
}

\begin{abstract}
The purpose of this study is to improve the potential energy recovery to electric energy in an electrohydraulic forklift system. The initial achieved result for energy saving ratio after structural optimization is $40 \%$. Component optimization is applied to the tested drive which consists of a DTC controlled electric servo motor directly running a reversible hydraulic pump. According to the study the energy efficiency and the energy recovery from the electro-hydraulic forklift system can be increased by $11 \%$ units. New ideas and directions of further research were obtained during the study.
\end{abstract}

Keywords: electric, electric vehicle, off-road vehicles, goods vehicles/trucks, hybrid, efficiency.

\section{INTRODUCTION}

Energy crisis and new emissions rules motivated to develop new proposals for energy efficient vehicles and non-road mobile machines (NRMM) [1,2]. Energy saving research in fluid power systems has mainly concentrated on improving single components' efficiencies [3-5]. When improving the overall energy efficiency it is not necessarily enough to reduce the energy consumption of a single component as in the worst case the system energy efficiency can even get worse when implementing a new energy efficient component but used in an inefficient operation area. However, by structural optimization there are ways to recover and re-use energy (kinetic and/or potential energy) in NRMM systems [6-11]. Energy regeneration can be realized through hydraulic or electric systems or by a combination of these technologies [12-14]. Therefore, component optimization such as energy storage, hydraulic oil and other single components to make new structure work more efficient become important [15-18]. In this paper, systems approach is used to evaluate the possibilities to increase the cycle efficiency in an already existing [15] modified by structural optimization setup.

The remainder of this paper is organized as follows. Section 2

Corresponding author. Tel.: +358505940496. E-mail address: Tatiana.minav@ aalto.fi (T.A. Minav). gives detail description of the system, test arrangements and formulas which were used for theoretical evaluation of the system. Section 3 contains discussion about possible improvement of the system with component optimization. Results of theoretical and empirical comparison and analysis are described in Section 4 and 5, respectably. Concluding remarks are presented in Section 6.

\section{OVERVIEW OF TEST ARRANGEMENTS}

Forklifts are mechanized equipment utilized for loading and storing of cargo into high shelving units. This loading device is in-use during all working days in some companies 7 days a week. During the experimental research, the conventional nonregenerative AC electric drive (Figure 1a) and the hydraulic pump of the forklift were replaced with the hydraulic and electric systems shown in Figure 1b. The grey lines indicate the oil flow during lifting and the black lines during lowering.

The test setup was built for the re-evaluation of the concept proposed for instance in [12]. The comparison of Figures 1a and $1 \mathrm{~b}$ provides a simplification of the hydraulic structure, which is achieved by replacing the more 'complicated' proportional valve by a 'simple' poppet valve [15]. (a)

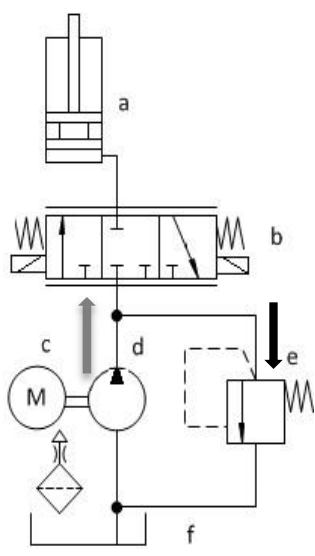

(b)

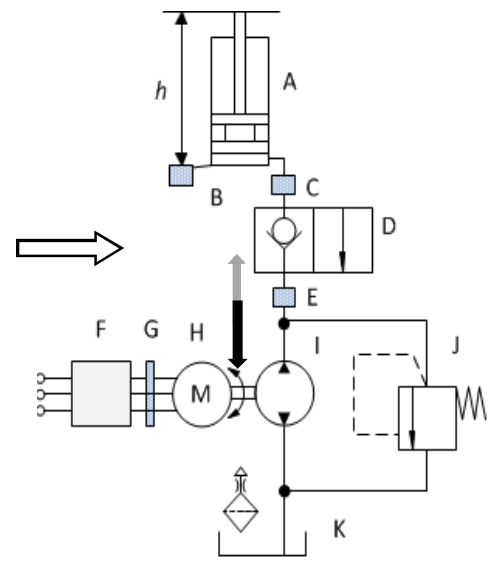

Fig. 1. (a) Conventional electro-hydraulic circuit of the main lift function of a forklift without energy regeneration from potential energy: a) single-acting 
cylinder, b) proportional valve, c) induction motor, d) pump, e) pressure relief valve, and f) oil tank; (b) Electric and hydraulic circuits of the main lift function with energy regeneration from potential energy in forklift: A) singleacting cylinder, B) position encoder SGW/SGI, C) pressure sensor, D) twoway normally closed poppet valve, E) pressure sensor, F) frequency converter, brake resistor $R_{\text {brake }}$ and DC-voltage and DC-current probes, G) phase current and voltage probes, H) permanent magnet synchronous motor/generator, I)hydraulic pump/motor, J) pressure relief valve, K)oil tank.

The position of the cylinder's piston is controlled directly through the amount of fluid delivered by the hydraulic pump which is directly driven by a speed-controlled electric servo motor drive. The two-way normally closed poppet valve as a safety valve was used in the system. The servomotor speed and the displacement of the hydraulic pump determine the oil flow and velocity of the fork during lifting and lowering cycles. While lowering a mass, the potential energy of the payload makes the hydraulic machine rotate as a motor, and the same time on a common shaft the electric machine acts as a frequency-converter-controlled generator.

Internal gear pump of $13.3 \mathrm{~cm}^{3} / \mathrm{rev}$ [19] and axial piston motor of $19 \mathrm{~cm}^{3} / \mathrm{rev}$ [20] were used in the tests. The $10 \mathrm{~kW}$ CFM112M servomotor by Sew-Eurodrive was equipped with a resolver [21]. An ABB ACSM1- 04 $\left.x^{4}\right) x^{5}$ )-046A-4 converter uses a resolver as the motor rotor position feedback [22]. Converter software Drive Studio by ABB was used to measure the rotating speed of the servomotor and to estimate the motor torque. Converter controls the generator torque accepting new torque command on $500 \mu$ s level, and it actively rectifies the regenerated electric energy to the DC link, where an accumulator should be connected. In this test case, the electric energy was converted into heat in the brake resistor $R_{\text {brake }}$ (with resistance of $25 \Omega$ ). WIKA S-10 pressure sensors manufactured were used to measure pressures between the pump and the two-way normally closed poppet valve, $p_{2}$ and between the pressure acting in cylinder piston side, $p_{1}$. Yokogawa PZ4000 Power analyzer with a sampling time of 10 $\mu$ s was used for restoring the voltage and current values. HITEC Zero-Flux B 2000 current sensors were used. The cylinder piston position (i.e. travel of the forks), $h$ were measured by a wire-actuated encoder SIKO SGW/SGI. The measured pressure $p_{1}$ and $p_{2}$, fork velocity, $v_{\mathrm{c}}$ and position, $h$ signals were recorded using the dSPACE DS 1105 PPC controller board with $\mathrm{I} / \mathrm{O}$ card.

The experimental setup was tested with payloads of 0,690 and $920 \mathrm{~kg}$ at different motor speeds $400-2000 \mathrm{rpm}$ (fork's velocity $0.2-0.5 \mathrm{~m} / \mathrm{s}$, respectably). Other speeds were not considered for the tests, as they were out of range conventional forklift. The tare weight of the moving fork system is around $700 \mathrm{~kg}$. Measured data (pressure, motor speed and torque, voltage and current) were used to obtained used power during single lifting or lowering cycle with a lifting zone. The amount of energy was attained by integrating from the measured power. The efficiencies of whole system work cycles and separate components were calculated using equations in Table 1.
TABLE 1

DEFINITIONS OF EFFICIENCY, POWER AND ENERGY

$\begin{aligned} & \text { System } \\ & \text { efficiency } \\ & \text { of lifting }\end{aligned} \eta_{\text {up_sys }}=\frac{E_{\text {pot }}}{E_{\text {motor }}}$

ifting

$E_{\text {pot }}=m g h$ is the potential

energy of the load $m$.

$E_{\text {motor }}$ is the input energy from the electric motor

$P_{\text {motor }}=u_{\mathrm{a}} i_{\mathrm{a}}+u_{\mathrm{b}} i_{\mathrm{b}}+u_{\mathrm{c}} i_{\mathrm{c}}$ as a sum of multiplication of phase voltages and currents.

Electric $\quad \eta=\frac{E_{\text {shaft }}}{E} \quad E_{\text {shaft }}$ is the mechanical energy motor $\quad \eta_{\text {motor }}=\frac{E_{\text {shaft }}}{E_{\text {motor }}} \quad$ from the motor shaft.

efficiency

$P_{\text {shaft }}=T \Omega$, where $T$ is motor torque and $\Omega$ is angular speed.

Pump $\quad \eta_{\text {pump }}=\frac{E_{\text {hydr }}}{E_{\text {h }}} \quad E_{\text {hydr }}$ is the hydraulic energy

efficiency $\quad \eta_{\text {pump }}=\overline{E_{\text {shaft }}} \quad$ output of the pump.

$P_{\text {hydr }}=p_{1} v_{\mathrm{c}} A$, where $A$ is cross area of cylinder.

\begin{tabular}{|c|c|c|}
\hline \multicolumn{3}{|c|}{ Lowering } \\
\hline & 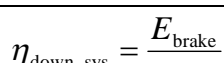 & $E_{\text {brake }}$ is the recovered energy \\
\hline $\begin{array}{l}\text { efficiency } \\
\text { of } \\
\text { lowering }\end{array}$ & $I_{\text {down_sys }}-\frac{E_{\text {pot }}}{2}$ & $\begin{array}{l}P_{\text {brake }}=i_{\text {brake }}^{2} R_{\text {brake }}, \text { where } \\
P_{\text {brake }} \text { is output energy from } \\
\text { brake resistor, } i_{\text {brake }} \text { is brake } \\
\text { current. }\end{array}$ \\
\hline $\begin{array}{l}\text { Electric } \\
\text { generator } \\
\text { efficiency }\end{array}$ & $\eta_{\text {gen }}=\frac{E_{\text {mot }}}{E_{\text {shaft }}}$ & $\begin{array}{l}E_{\text {shaft }} \text { is the output energy from } \\
\text { the shaft }\end{array}$ \\
\hline $\begin{array}{l}\text { Efficiency } \\
\text { of the } \\
\text { hydraulic } \\
\text { motor }\end{array}$ & $\eta_{\text {mot }}=\frac{E_{\text {shaft }}}{E_{\text {hydr }}}$ & $\begin{array}{l}\eta_{\text {mot }} \text { is the efficiency of the } \\
\text { hydraulic motor }\end{array}$ \\
\hline
\end{tabular}

\begin{tabular}{lc}
\hline \multicolumn{1}{c}{ Cycle } \\
\hline $\begin{array}{l}\text { Cycle } \\
\text { efficiency }\end{array}$ & $\eta_{\text {cycle }}=\eta_{\text {down_sys }} \cdot \eta_{\text {up_sys }}$ \\
\hline
\end{tabular}

\section{BARIERS TO HIGH ENERGY EFFICIENCY}

This section begins by presenting the paper' overall discussion about possible improvement in the system, which can be achieved by replacing single components. Each subsection of component optimization ends with a brief presentation of how the change effects in the different case studies.

\section{A. Motor drive}

The main requirement of the prime mover is that it can controllably generate sufficient torque for the purpose. The maximum lifting payload of the forklift tested is $1500 \mathrm{~kg}$. For the maximum payload the hydraulic pump needed $50 \mathrm{Nm}$ shaft torque. This is one factor which defines the boundary conditions for the prime mover.

Conventionally in forklifts induction motor (IM) drives are used. In the experimental setup, however, a DTC controlled permanent magnet machine was employed due to its good dynamic response and high efficiency [15]. Table 2 shows an example of the measurements of the system efficiency for lowering for different type of prime movers. 
TABLE 2

MEASURED SYSTEM EFFICIENCY FOR LOWERING WITH PAYLOAD OF 920 KG

\begin{tabular}{lcc}
\hline $\begin{array}{l}\text { Fork } \\
\text { velocity, } \\
{[\mathrm{m} / \mathrm{s}]}\end{array}$ & \multicolumn{2}{c}{ System efficiency, [\%] } \\
\cline { 2 - 3 } & PMSM & IM \\
\hline 0.14 & 49 & 27.6 \\
0.2 & 55.6 & 35.6 \\
0.37 & 56.3 & 38.9 \\
0.53 & 56.7 & 38 \\
\hline
\end{tabular}

According to [24], by changing an IM to a PMSM a system efficiency improvement was achieved up to 20 or $10 \%$-units during lowering and lifting, respectively.

\section{B. Pump}

Pump selection includes many factors like the flow rate, speed, pressure, cost, maintenance, performance, and reliability. Gear and piston pumps are the main pump types available for the fluid power applications in mobile working machines. There are many subtypes available for these pumps. Gear pumps are available e.g. for 35-200 bar, 1200-2500 rpm, 80-90\% efficiency; Piston pumps are typically available for 150-800 bar, 1200-3000 rpm, 85-98 \% efficiency [25].

Conventional forklift manufacturers usually rely on external or internal gear pumps, due to their low price, and acceptable pressure and performance ratio. The efficiency of these machines is, however low, and they are not necessarily reciprocal in operation. Figure 2 shows the measured system efficiency for lowering and lifting for different pumps.

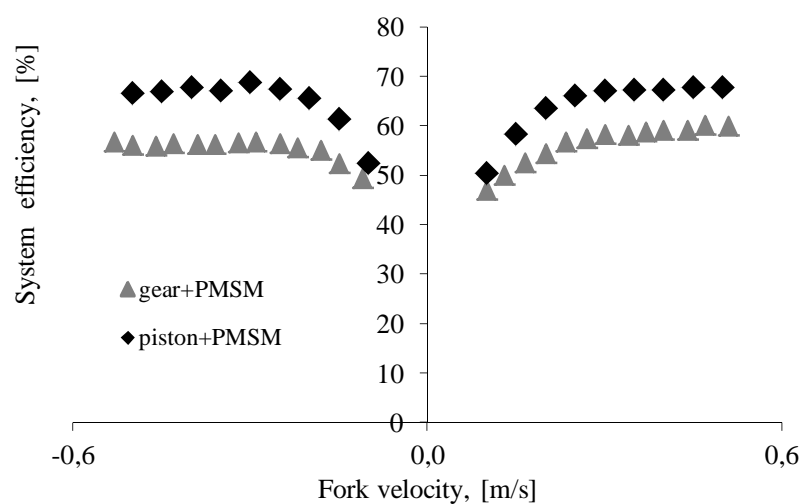

Fig.2. Measured system efficiency for lowering (negative speed) and lifting (positive speed) with payload of $920 \mathrm{~kg}$ with internal gear and axial piston pump.

According to Figure 2, by replacing the internal gear pump by an axial piston pump; the system efficiency was improved about $10 \%$-units.

Therefore, initial requirements for the pump are: flow rate requirements $1.3-1.4 \times 10^{-5} \mathrm{~m}^{3} / \mathrm{rev}$, and maximum pressure requirement of $180 \mathrm{bar}$. The speed of the pump is usually limited to $3000 \mathrm{rpm}$. Additionally, compared to conventional requirements, the new pump should have the possibility to work in four-quadrant modes as introduced in [26]. Conventional commercially available pumps and motors are capable to operate like that, but the durability in such varying operation is needed to be tested. Recently, some manufactures have developed new product for these purposes. According
[27], hydraulic machine chosen for integration to electrohydraulic energy converter is capable of operating as hydraulic pump and hydraulic motor. Figure 3 shows the efficiency map of certain fixed-displacement axial piston pump/motor in pumping mode (positive speed) and motoring mode(negative speed).

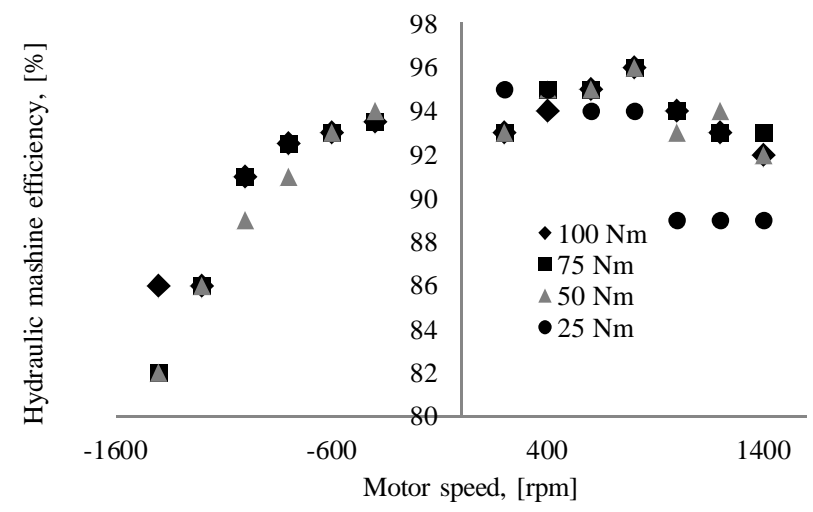

Fig. 3. Measured hydraulic machine efficiency for lowering (negative speed) and lifting (positive speed).

It can be seen that the highest efficiency region is concentrated at medium speeds at all torques. The best pumping efficiency measured s $96 \%$. In the motoring mode, it can be seen that the highest efficiency region is concentrated at low and medium speeds. The best motoring efficiency is 94 $\%$.

According to [28], the FCM24 floating cup pump/motor has been developed for hydraulic hybrid vehicles with maximum efficiency of $97 \%$ for both motoring and pumping modes. Table 3 shows the selected efficiency points of the FCM24 for motor operation for oil temperature $55^{\circ} \mathrm{C}$ suitable for forklift operation range. The efficiency exceeds $96 \%$ on a broad operating range.

TABLE 3

SELECTED EFFICIENCY POINTS OF THE FCM24 FOR MOTOR OPERATION FOR OIL TEMPERATURE $55^{\circ} \mathrm{C}$

\begin{tabular}{lccll}
\hline efficiency, [\%] & \multicolumn{4}{c}{ supply pressure, [bar] } \\
\hline motor speed, [rpm] & 50 & 100 & 200 & 250 \\
\hline 500 & 97 & 96 & 95 & 94 \\
1000 & 95 & 96.5 & 96.5 & 96 \\
2000 & 91 & 94.5 & 96 & 96 \\
3000 & 88 & 93 & 95 & 95.5 \\
\hline
\end{tabular}

It can be concluded that to achieve a high efficiency, work should be performed in the area of slow and middle speeds for lowering (motoring mode) and for lifting (pumping mode) in middle speeds.

\section{Valves-Digital components}

A conventional proportional control valve is the main control unit and it works as described in the following. The pressure relief valve is used to adjust the system pressure to the operating level required by the actuator.

The flow control valve limits the maximum volume flow to the hydraulic cylinder, ensuring that it moves at the correct velocity. Control valves ensure correct direction of the flow in the system. It is a well-known fact that conventional valves are 
characterized by the resistance and internal leakage. Due to this fact, $40 \%$ consumption is lost in a hydraulic boom, according to [29].

Digital valves are emerging as one of the energy saving technologies in hydraulics; they also offer positive possibilities for regeneration. Reference [30] shows that the reduction of losses in a hydraulic boom in a simulated case is about $22 \%$ by switching to Digital Hydraulic Power Management System (DHPMS). According to [31], digital fluid power technology has rapidly achieved the status of potential modern fluid power technology. Digital components compared to traditional components are more robust and simpler, have higher efficiency, but are noisy and require additional control technology [31]. Digital valves, pumps, transformers and actuators are already available [32]. So far there are applications in the market with digital valves, Parker [33] already offer for sale variety of digital valves. By using digital hydraulics it is possible to achieve better performance, better fault tolerance and significantly reduced power losses up to $50 \%$ [34].

\section{Oil and Temperature}

According to [18, 35-37] also the quality of oil can improve the efficiency of a system significantly. It was shown in [18] that correct oil in big machines, such as excavators, can reduce the energy consumption even by $25 \%$. It was achieved by increasing the volumetric efficiency of pump and reducing frictional losses in valves. Figure 4 shows the system efficiency versus motor speed with forklift test setup. Performed tests show increasing efficiency in average up to 3 $\%$-units during lowering. Table 4 shows the used oil properties. Oil A is conventional multi-grade hydraulic oil. Oil $\mathrm{B}$ is high performance oil. Both oils has viscosity grade ISO VG 32 .

Lifting system efficiency can be considered unchanged as based line A is very good oil and temperature variation is limited, and improvement is not dramatic as in [18]. Measurements were performed with ambient temperature of $23 \mathrm{C}$.

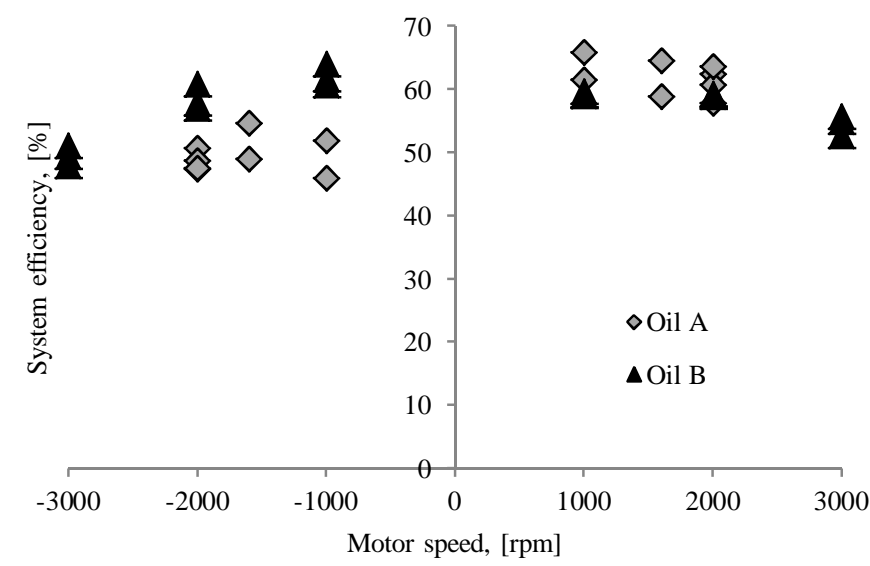

Fig. 4. Measured system efficiency for lowering (negative speed) and lifting (positive speed) with payload of $500 \mathrm{~kg}$ with internal gear with different oils.
OIL PROPERTIES.

\begin{tabular}{lll}
\hline Unit & Oil A & Oil B \\
\hline $\mathrm{KV} 40^{\circ} \mathrm{C}, \mathrm{mm}^{2} / \mathrm{s}$ & 32.41 & 32.10 \\
$\mathrm{KV} 100^{\circ} \mathrm{C}, \mathrm{mm}^{2} / \mathrm{s}$ & 7.26 & 6.16 \\
$\mathrm{VI}($ viscosity index) & 199 & 144 \\
$\mathrm{KV}-40^{\circ} \mathrm{C}, \mathrm{mm}^{2} / \mathrm{s}$ & $\begin{array}{l}\text { too thick to } \\
\text { measure }\end{array}$ & 9022 \\
Pour Point, ${ }^{\circ} \mathrm{C}$ & -42 & -51 \\
Brookfield $-26^{\circ} \mathrm{C}$, & 1750 & 1500 \\
$\mathrm{mPas}$ & 329000 & 7350 \\
$\begin{array}{l}\text { Brookfield }-40^{\circ} \mathrm{C} \\
\text { (incl. repeat), } \mathrm{mPas}\end{array}$ & & \\
\hline
\end{tabular}

Table 4 shows that Oil A has a very high viscosity index (VI) which is expected to provide outstanding volumetric efficiency and Oil B has a medium VI and excellent low temperature properties which favor mechanical efficiency.

\section{E. Energy storage}

The common energy storages in electric regeneration setups are batteries and super capacitors. It is relatively economical to apply these components as electric energy storage elements are existing technology in forklifts. Commonly, lead-acid batteries are used in commercial forklifts, each movement of fork and moving load around reduces the energy stored in the battery during working time. Because of this fact batteryoperated machines are generally considered being limited due to the capacity of the battery [38]. According to the manufacturers, a power-electronic charger device provides about 85-95 \% efficiency. The lead-acid battery chargedischarge efficiency varies between 76-90\%. According to [39], the energy density for a standard lead-acid battery is 30$50 \mathrm{Wh} / \mathrm{kg}$. Lately batteries as energy storages have improved their performance significantly, but high prices are still an important showstopper [16]. Research in [40] examined the opportunities to store and reuse energy recovered from a hydraulic system of a forklift by using some of the easily available practical energy storages (lead-acid battery, super capacitor and hydraulic accumulator). It provided analyses of the setups from the energy efficiency perspective: The cycle efficiencies and the energy-saving ratios for different payloads and speeds were calculated. In conclusion, a combination of modern lead-acid battery, super capacitor and a simple power diode was recommended the most energy efficient solution for verification by measurements. The expected energy efficiency varies between 90 and $95 \%$ for different charge-discharge load cycles. An alternative but maybe still an expensive method is to use a lithium-titanate battery. The most important advantage of this battery type is 10 million operation cycles with a low depth of discharge (DOD) and up to 2000 cycles with $100 \%$ DOD [41]. Figure 5 shows Chart of the lithiumtitanate battery's Coulombic efficiency for different payloads (currents) and State of charge (SOC) for a single liftinglowering cycle of forklift. Battery's high efficiency region is located in low current and high SOC regions. This gives recommendation to operate forklift truck in low currents and high SOC charges to maintain high battery's efficiency. Efficiency of $95 \%$ will be used for analysis as it is cover region of forklift operation. 


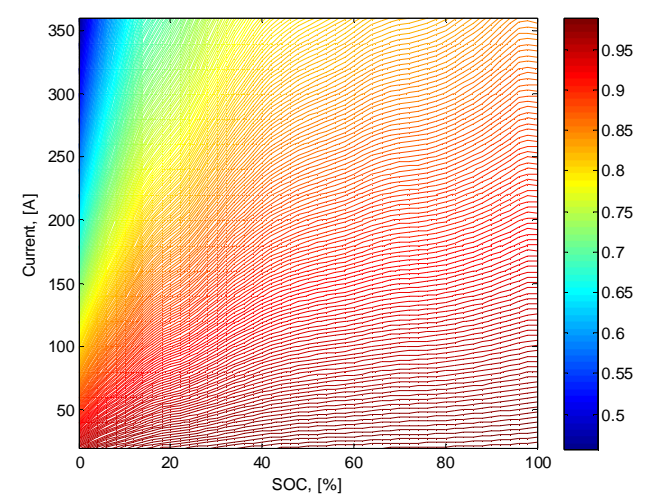

Fig. 5. Chart of the Battery's Coulombic efficiency for different payloads (currents) and SOC for a single lifting-lowering cycle.

\section{THEORETICAL RESULTS}

This section combines findings from above discussion. The system efficiency of the experimental setup was calculated as:

$$
\eta_{\mathrm{sys}}=\eta_{\mathrm{CON}} \cdot \eta_{\mathrm{EM}} \cdot \eta_{\mathrm{HM}} \cdot \eta_{\mathrm{VP}} \cdot \eta_{\mathrm{C}}
$$

where the subscript $\mathrm{CON}$ denotes the frequency converter, EM the electric machine, HM the hydraulic machine, VP the pipes and valves, and $\mathrm{C}$ the hydraulic cylinder. The efficiency of valves and pipes are combined as one value of pressure losses in piping, valves and fittings. In our test setup, the power losses vary between 5-10\% depending on the operation mode [17]. The efficiency of the cylinder was taken to $95 \%$ [42]. Table 5 shows the efficiency definitions for the experimental setup and possible improvement, which can be achieved by replacing components based on the recommendations above for.

TABLE 5

\begin{tabular}{|c|c|c|c|}
\hline Component & $\begin{array}{l}\text { Theoretical } \\
\text { maximum } \\
\text { efficiency of } \\
\text { conventional } \\
\text { component }\end{array}$ & $\begin{array}{l}\text { Theoretical } \\
\text { maximum } \\
\text { efficiency } \\
\text { of replacing } \\
\text { component }\end{array}$ & Improvement \\
\hline motor & $92 \%$ & $94 \%$ & $2 \%$-units \\
\hline converter & $97 \%$ & $98 \%$ & $1 \%$-unit \\
\hline pump & $90 \%$ & $96 \%$ & $6 \%$-units \\
\hline hydr. motor & $90 \%$ & $96 \%$ & $6 \%$-units \\
\hline valve & $91 \%$ & $94 \%$ & $3 \%$-unit \\
\hline cylinder & $95 \%$ & $95 \%$ & - \\
\hline oil & Oil A & Oil B & 1 to $3 \%$-unit \\
\hline $\begin{array}{l}\text { battery } \\
\text { system } \\
\text { efficiency }\end{array}$ & $90 \%$ & $95 \%$ & $5 \%$-units \\
\hline lifting & $63 \%$ & $75 \%$ & $12 \%$-units \\
\hline lowering & $63 \%$ & $75 \%$ & $12 \%$-units \\
\hline $\begin{array}{l}\text { cycle } \\
\text { efficiency }\end{array}$ & $40 \%$ & $56 \%$ & $16 \%$-units \\
\hline
\end{tabular}

Based on the information, demonstrated in Table 5, the improvement of the system efficiency can be $6 \%$-units by changing the pump, $2 \%$-units by changing the motor drive, 5 $\%$-units by choosing proper energy storage. Following section contains measurements results achieved with a new pump and motor.

\section{MEASUREMENTS}

Figures 6 and 7 show measurement results achieved using the axial piston machine and the $10 \mathrm{~kW}$ PMSM. In this test the oil A was used and energy was recovered to the brake resistor which was acting as "energy storage".

Figure 6 illustrates system efficiency for lifting and lowering with payloads 0,690 and $920 \mathrm{~kg}$. In figure positive speed corresponds to lifting and negative speed - lowering movements.

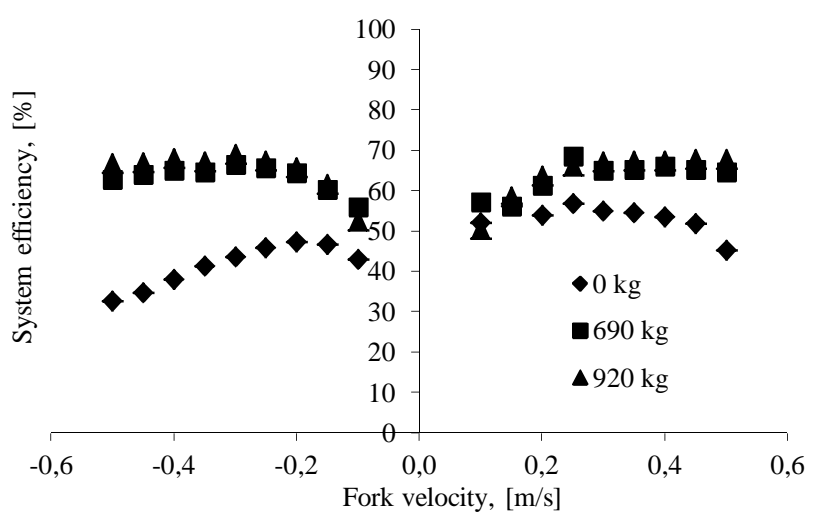

Fig.6. System efficiency with payloads of $0 \mathrm{~kg}, 690 \mathrm{~kg}$ and $920 \mathrm{~kg}$ for lifting (positive speed) and lowering (negative speed) movements (*estimated inverter efficiency was used for lifting).

In Figure 6 average lifting efficiency is about $68 \%$, and during lowering is $67 \%$. In this particular case, pump efficiency varies 84 to $69 \%$ depending on speed and payload during lifting and during lowering maximum hydraulic motor efficiency is $85 \%$. Electric machine efficiency for lifting and lowering is varies in range 94 to $74 \%$. Highest electric machine efficiency is located in rated region of electric motor. Table 6 contains example of efficiency definitions for experimental setup for fork velocity $0.5 \mathrm{~m} / \mathrm{s}$ and payload 920 $\mathrm{kg}$. Motor speed $2000 \mathrm{rpm}$ correspond to fork velocity $0.5 \mathrm{~m} / \mathrm{s}$.

TABLE 6

EFFICIENCY DEFINITIONS FOR EXPERIMENTAL SETUP FOR FORK VELOCITY $0.5 \mathrm{M} / \mathrm{s}$ PAYLOAD $920 \mathrm{KG}$

\begin{tabular}{|c|c|c|c|}
\hline Component & $\begin{array}{l}\text { Measured } \\
\text { efficiency of } \\
\text { component }\end{array}$ & $\begin{array}{l}\text { Theoretical } \\
\text { maximum } \\
\text { efficiency of } \\
\text { replacing } \\
\text { component** }\end{array}$ & Improvement \\
\hline \multicolumn{4}{|c|}{ electric machine } \\
\hline motor & $91 \%$ & $94 \%$ & $3 \%$-units \\
\hline generator & $94 \%$ & $94 \%$ & - \\
\hline converter & $95 \% *$ & $98 \%$ & $3 \%$-unit \\
\hline \multicolumn{4}{|c|}{ hydraulic machine } \\
\hline pump & $84 \%$ & $96 \%$ & $12 \%$-units \\
\hline motor & $80 \%$ & $96 \%$ & $16 \%$-units \\
\hline oil & Oil A & Oil B & - \\
\hline $\begin{array}{l}\text { battery } \\
\text { system } \\
\text { efficiency }\end{array}$ & - & $95 \%$ & - \\
\hline lifting & $68 \%$ & $75 \%$ & $7 \%$-units \\
\hline lowering & $67 \%$ & $75 \%$ & $8 \%$-units \\
\hline $\begin{array}{l}\text { cycle } \\
\text { efficiency }\end{array}$ & $45 \%$ & $56 \%$ & $11 \%$-units \\
\hline
\end{tabular}


From Table 6 it can be seen, that in current setup configuration effect of hydraulic machine is dominated. By applying suggestions the system efficiency during lifting can be improved by $7 \%$-units compared to the experimental setup and the cycle efficiency by $11 \%$-units. As payload stays constant and valve losses are neglected the same theoretical improvement level used for different speeds to define the new cycle efficiency.

Figure 7 shows that the measured cycle efficiency and example of calculated cycle efficiency which indicated by sign $\times$.

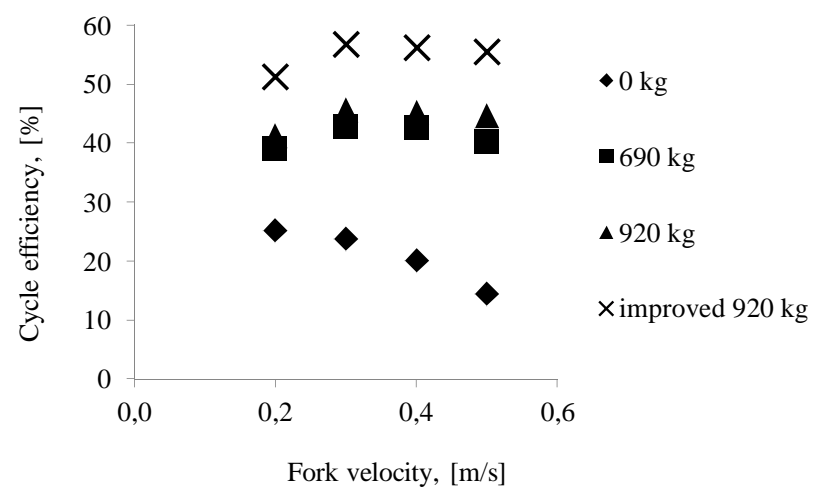

Fig.7. Measured cycle efficiency with payloads of $0 \mathrm{~kg}, 690 \mathrm{~kg}$ and $920 \mathrm{~kg}$ (*estimated inverter efficiency was used for lifting) and indicated by sign $\times$ calculated cycle efficiency for $920 \mathrm{~kg}$.

Figure 8 shows that the measured cycle efficiency with updated setup: with PMSM, axial piston motor. In this test the oil B was used and lithium-titanate battery was used as energy storage. Figure 8 illustrates cycle efficiency for lifting and lowering with payloads 0,500 and $1000 \mathrm{~kg}$.

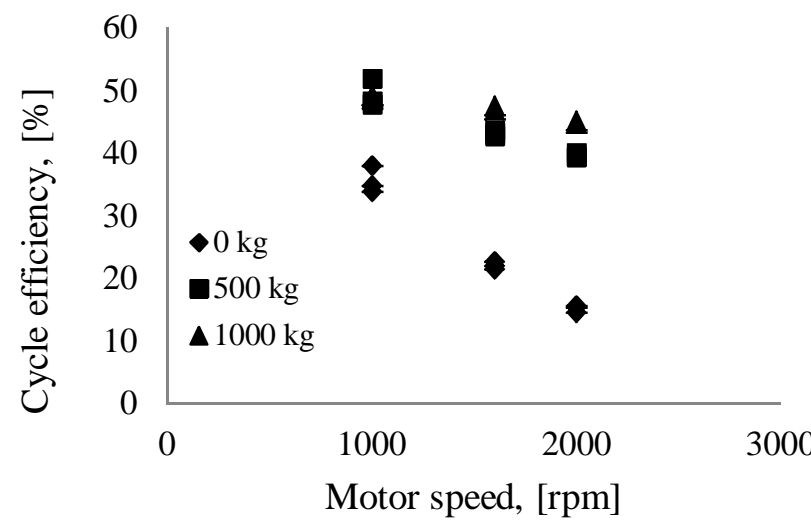

Fig.8. Measured cycle efficiency with payloads of $0 \mathrm{~kg}, 500 \mathrm{~kg}$ and $1000 \mathrm{~kg}$. Setup configuration with PMSM with oil B, lithium titanate battery and axial piston motor was used.

Compare Figure 8 to Figure 7 improvement is about 1-2\%units of cycle efficiency in high speeds and big payloads. Measurements in low motor speeds showed improvement up to $7 \%$-units of cycle efficiency and confirm theoretical calculation performed in Table 6. Therefore, it can be conclude that further component optimization can lead to better cycle efficiency and high energy regeneration in forklift.

\section{CONCLUSION}

The presented work concentrated on analyzing the possible improvements in an electro-hydraulic forklift truck with an energy recovery option. It was shown that potential energy recovery and payload control by an electric servo drive are feasible in an electro-hydraulic forklift trucks. Efficiency behaviours of electro-hydraulic system components and the cycle efficiencies of the forklift system were determined. The theoretical efficiency estimation was based on combining manufacturer's curves and measurement results of the efficiency of the experimental setup.

Research results showed that in current setup configuration effect of hydraulic machine is dominating. Efficiency of hydraulic machine can be improved up to $16 \%$-units by choosing specially designed for two quadrant of operation pump/motor. It was shown that it is possible to increase the cycle energy-efficiency in an electro-hydraulic forklift by 11 $\%$-units compare to experimental setup and by $16 \%$ compared to conventional forklift by applying suggested changes.

\section{Acknowledgment}

The research was enabled by the financial support of Tekes, the Finnish Funding Agency for Technology and Innovation, European Union, European Regional Development Fund and Regional council of South Karelia and FIMA (Forum for Intelligent machines) at the Institute of Energy Technology, Department of Electrical Engineering and LUT Mechanical Engineering at Lappeenranta University of Technology.

\section{REFERENCES}

[1] Chiara F. and Canova M., A review of energy consumption, management, and recovery in automotive systems, with considerations of future trends, Proceedings of the Institution of Mechanical Engineers, Part D: Journal of Automobile Engineering, June 2013; vol. 227, 6: pp. 914-936., first published on March 25, 2013.

[2] EPA. Clean Air Nonroad Diesel - Tier 4 Final Rule [Internet], [cited 14 January 2010] available at: http://www.epa.gov/nonroaddiesel/2004fr.htm.

[3] Gao Y-J, Huang R., and Zhang Q., A comparison of three steering controllers for off-road vehicles, Proceedings of the Institution of Mechanical Engineers, Part D: Journal of Automobile Engineering, December 1, 2008; vol. 222, 12: pp. 2321-2336.

[4] Midgley W.J.B., Cathcart H., and Cebon D., Modelling of hydraulic regenerative braking systems for heavy vehicles, Proceedings of the Institution of Mechanical Engineers, Part D: Journal of Automobile Engineering, July 2013; vol. 227, 7: pp. 1072-1084., first published on January 15, 2013.

[5] Kunze G., Mobile construction machinery - trends and new developments, ATZonline, [Internet], April 2010, [cited 10 January, 2011]. Available from: http: //www.atzonline.com.

[6] Diego-Ayala U., Martinez-Gonzalez P., McGlashan N., and Pullen K. R., The mechanical hybrid vehicle: An investigation of a flywheel-based vehicular regenerative energy capture system, Proceedings of the Institution of Mechanical Engineers, Part D: Journal of Automobile Engineering, November 1, 2008; vol. 222, 11: pp. 2087-2101.

[7] Ho T. H., Ahn K. K., Design and control of a closed-loop hydraulic energy-regenerative system. Journal Automation in construction. Vol. 22, March 2012, pp. 444-458.

[8] Zhang Z., Chen J. and Wu B., The control strategy of optimal brake energy recovery for a parallel hydraulic hybrid vehicle, Proceedings of the Institution of Mechanical Engineers, Part D: Journal of Automobile Engineering, November 2012; vol. 226, 11: pp. 1445-1453, first published on May 25, 2012 
[9] Ye M., Bai Z-F., and Cao B-G., Energy recovery for battery electric vehicles, Proceedings of the Institution of Mechanical Engineers, Part D: Journal of Automobile Engineering, October 1, 2008; vol. 222, 10: pp. 1827-1839.

[10] Zhang J., Lv C., Gou J., and Kong D., Cooperative control of regenerative braking and hydraulic braking of an electrified passenger car, Proceedings of the Institution of Mechanical Engineers, Part D: Journal of Automobile Engineering, October 2012; vol. 226, 10: pp. 1289-1302., first published on April 25, 2012.

[11] Diego-Ayala U., Martinez-Gonzalez P., McGlashan N., and Pullen K. R., The mechanical hybrid vehicle: An investigation of a flywheel-based vehicular regenerative energy capture system, Proceedings of the Institution of Mechanical Engineers, Part D: Journal of Automobile Engineering, November 1, 2008; vol. 222, 11: pp. 2087-2101.

[12] Andersen T. O., Hansen M. R., Pedersen H. C. and Conrad F. Regeneration of potential energy in hydraulic forklift truck. In: The 6th International Conference on Fluid Power Transmission and Control, 2005, pp. 302-306, Hangzhou.

[13] Minav T., Laurila L., Immonen P., Pyrhönen J., Vtorov V. and Niemelä M. Electric energy recovery system for a hydraulic forklift - theoretical and experimental evaluation, IET Electric Power Applications, Vol. 5, issue 4, April 2011

[14] Hui S., Junqing J.. Research on the system configuration and energy control strategy for parallel hydraulic hybrid loader, Journal Automation in Construction, Vol. 19, Issue 2, March 2010, pp. 213-220.

[15] Minav, T. Electric-drive-based control and electric energy regeneration in a hydraulic system. PhD thesis, Acta Universitatis Lappeenrantaensis 436, Lappeenranta University of Technology, Finland, 2011.

[16] Budde-Meiwes H., Drillkens J., Lunz B., Muennix J., Rothgang S., Kowal J., and Uwe Sauer D., A review of current automotive battery technology and future prospect, Proceedings of the Institution of Mechanical Engineers, Part D: Journal of Automobile Engineering, May 2013; vol. 227, 5: pp. 761-776., first published on April 19, 2013

[17] Minav T., Laurila L. and Pyrhönen J., Permanent Magnet Synchronous Machine Sizing: Effect on the Energy Efficiency of an Electro-hydraulic Forklift. Transactions on Industrial Electronics.59 (6) (2012) pp. 2466.

[18] Neveu C. D., Herzog S. N, Simko R.P., Alibert M.J., Influence of hydraulic fluid selection on vane pump efficiency and fluid temperature, NCFP I08-2.5.

[19] Eckerle, Hydraulic division. EIPS 2 Internal gear pumps.[Online]. Accessed 20 April 2008, available at: http: //www.eckerle.com

[20] Parker, Hydraulic Motor/pump Series F11/F12. [Online], Accessed 8 October 2008, available at: http://www.parker.com.

[21] SEW Eurodrive. The DS/CM synchronous servomotors from SEWEurodrive. [Online]. available at: http: //www.eurodrive.com

[22] ABB: Motion Control program Firmware. [Online], accessed 13 November 2007, available at: http://www.abb.com

[23] Altairnano, [Online]. available at: http://www.altairnano.com/

[24] Minav T., Laurila L., Pyrhönen J., Effect of electric motor on the energy efficiency of elecro-hydraulic forklift. In: Energy Efficiency - A Bridge to Low Carbon Economy, ISBN: 978-953-51-0340-0, publisher InTech, 2012.

[25] Merritt H. E. Hydraulic control systems. John Wiley \& Sons,1967, p.354.

[26] Rahmfeld R. Development and Control of Energy Saving Hydraulic Servo Drives for Mobile Systems. PhD thesis, Technical University of Hamburg-Harburg, Germany, 2002.

[27] Ponomarev P., Tooth-coil permanent magnet synchronous machine design for special applications, $\mathrm{PhD}$ thesis, Acta Universitatis Lappeenrantaensis 531, Lappeenranta University of Technology, Finland, 2013.

[28] Achten P., Vael G., van den Brink T., Potma J., Schellekens M., Efficiency measurements of the hybrid motor/pump, Innas BV, Breda, the Netherlands. In: The Twelfth Scandinavian International Conference on Fluid Power, May 18-20, 2011, Tampere, Finland.

[29] Liang X., Virvalo T., What's wrong with energy utilization in hydraulic cranes. In: The 5th international conference on fluid power transmission and control, 2001. Hangzhou, China.

[30] Karvonen M., Heikkilä M., Huova M., Linjama M. and Huhtala K. Simulation study - improvement efficiency in mobile boom by using digital hydraulic power management system. In: The Twelfth Scandinavian International Conference on Fluid Power, May 18-20, 2011, Tampere, Finland.
[31] Linjama M. Digital fluid power-state of the art. In: The Twelfth Scandinavian International Conference on Fluid Power, May 18-20, 2011, Tampere, Finland

[32] Wadsley L., Optimal System Solutions Enabled by Digital Pumps, http://www.artemisip.com/

[33] Parker digital valves, www.parker.com

[34] Linjama, M., Vilenius, M., Digital Hydraulics-towards perfect valve technology, Digitalna Hydravlika, 2008, pp. 138-148.

[35] Alibert M.J., Deneen D.H., Herzog S.N, Neveu C.D., Impact of hydromechanical losses on hydraulic pump efficiency as a function of pressure, temperature and fluid isometric properties. In: STLE PaperMay 2010.

[36] Alibert M.J., Görlitzer H., Herzog S. N, Neveu C. D. Efficiency advantages in Vane, Piston and gear Pumps -What High VI hydraulic fluids Can Do for You! In: 8th International Fluid Power Conference, Dresden, March 2012.

[37] Hamaguchi H., Ohkawa S., Placek D., Alibert M.J., Hydraulic fluid influence of piston pump efficiency. In: The 12th annual Fuels and Lubes Asia conference, March 1-3, 2006.

[38] Minav, T., Murashko, K., Laurila, L., and Pyrhönen, J., Forklift with a lithium-titanate battery during a lifting/lowering cycle: Analysis of the recuperation. Journal Automation in Construction, May 2013, in press.

[39] Root M. The TAB Battery book: An in-depth guide to construction, design and use, McGraw-Hill, New York, 2011, p.235.

[40] Minav, T., Virtanen, A., Laurila, L., and Pyrhönen, J., Storage of energy recovered from an industrial forklift. Journal Automation in Construction,Vol.22, March 2012, Pages 506-515.

[41] Giuliano M. R., Advani S. G., Prasad A. K., Thermal analysis and management of lithium-titanate batteries, Journal Power Sources, 2011, p.6517-6524.

[42] Majumdar, S. R. Oil Hydraulic Systems principles and maintaince. McGraw-Hill, 2002, p. 548 